\title{
Playing at Serial Acquisitions
}

\author{
Han Smit \\ Thras Moraitis
}

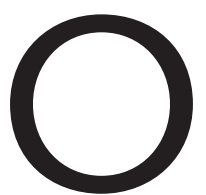

ver just a few years in the early 2000s, then-CEO Chris Gent

grew Vodafone from a small UK-based mobile operator into the world leader, with over 240 million customers. He did this

via a sequence of 26 strategic equity transactions, including the acquisition of AirTouch and transactions leading to the creation of the Verizon wireless business in the U.S.; a bitter takeover battle for Germany's Mannesmann; and many Asian alliances such as China Mobile link.

Today's economy is characterized by uncertainty, globalization, and the rapid emergence of significant new markets (most notably in China and India) with significant consumer bases, skills, and low-cost production capacity. The need for increased efficiency in such an environment makes Vodafone's global acquisition strategy enviable. Management teams typically envision a series of transactions based on buy-and-build principles, in which they initially acquire a "platform" in a new geography and then leverage their newly acquired competencies and assets into follow-on acquisitions over a wider geographic and customer base.

Looking at Vodafone's acquisition story, Chris Gent played his cards well, while rivals and financial markets acted irrationally in some instances. Using Vodafone's shares as a currency for its acquisitions, Gent created a successful global telecoms brand while some of Vodafone's rivals, failing to see the strategic value of acquisitions, remained imprudently conservative. However, even Gent may have made some serial acquisition errors on the road to building the world's leading telecoms company. He was sometimes accused of hubris and

This article is a compilation of ideas from the authors' forthcoming book Playing at Acquisition Games (Princeton University Press, 2012) that provides new tools based on behavioral economics, principles from options theory, and game theory. 
some of Vodafone's acquisitions were thought to be overpriced by the financial market community at the time.

However, executing a successful global acquisition strategy without making risky decisions is a difficult task-in the real and uncertain competitive world, macroeconomic change or competitor preemption may render apparently realistic targets unavailable or unattractively expensive. All management teams face the same basic dilemmas when making decisions: on the one hand, any target carries the risk of overpayment, which may be founded on unconscious irrational justifications, such as an over-optimistic expectation of synergies or growth opportunities, or becoming trapped in an escalating bidding contest. On the Han T.J. Smit is the Professor of Corporate Finance at Erasmus University Rotterdam in the Netherlands. <jsmit@few.eur.nl> other hand, in consolidating industries in particular, opportunities are limited and a missed chance is a very real threat. UnderThras Moraitis is Executive General Manager, Group Strategy and Corporate Affairs and an Executive Board member at Xstrata. bidding—failing to pay the price required to secure a critical target-may result from "framing" the opportunity in isolation by failing to recognize new growth options and to fully appreciate the value of a target as part of a larger consolidation strategy. The imperative to select appropriate targets and then execute the relevant transactions successfully is far greater in a serial acquisition strategy context, where failure at one step of the process could cause the strategy to stall or to break down later on.

This kind of strategic acquisition dilemma can determine the firm's future success, its market value, and even-in the challenging landscape of industry consolidation-its very survival. Yet managers too often make these decisions based on intuition and experience alone, leaving them vulnerable to the pitfalls of cognitive biases, with little guidance from rational tools to analyze and assist their serial acquisition decisions.

Novel company valuation methods (such as real option game valuation) are a relatively new field that has been hitherto separated from behavioral literature. We argue that a structured and rational quantitative analysis, using a modified option game toolkit, could help mitigate several management biases. We focus on a particular tension: how cognitive biases can "infect" rational analysis and lead executives to manipulate-inadvertently or knowingly—their analyses to get the answers they expect or require. The specific advantage of the rational approach we propose is that it allows for adjustments to prevent such "irrational infection" of the rational analysis of valuation.

\section{Six Potential Pitfalls in the Execution of a Serial Acquisition Strategy}

Fragmented industries are increasingly becoming consolidated, either pro-cyclically (to take advantage of favorable investment opportunities or in the pursuit of scale and diversification, as in telecoms or mining) or counter-cyclically (driven by the need for efficiency, as in banking, airlines, or car manufac- 
turing). Arguments based on efficiency and market power, the rise of the BRIC economies, and the global integration of financial and product flows are creating an imperative for globalization in mining, banking, airlines, and steel.

What the strategies of Vodafone, Xstrata (mining), or Arcelor Mittal (steel) have in common is that they are the serial execution of transactions in pursuit of an external accumulation of assets. They adhere to traditional buyand-build principles, in which an investor initially acquires one or more platforms and then leverages their newly acquired core competencies and assets onto follow-on acquisitions over a wider geographic, product, or customer base.

The strategy pursued by Vodafone during the early 2000s was a classic example of global consolidation. After a successful marketing campaign had secured it a dominant position in its UK home market, its acquisitions in the U.S., Europe, China, and Japan gave it a platform to create a global telecom brand. Vodafone gained a strong position in the U.S. when it outbid Bell Atlantic to buy AirTouch for $\$ 62$ billion in January 1999. The merger created one of the world's largest international mobile telecoms companies, with an extensive presence that covered most of Europe and the United States. Vodafone considered a number of subsequent options in the U.S., including making a move to combine the U.S. mobile phone interests of Vodafone AirTouch and Bell Atlantic. ${ }^{1}$

In 2000, the company strengthened its position in Europe when it launched a \$205 billion hostile bid for Germany's Mannesmann telecoms group in a battle that remains one of the largest hostile takeovers in history. This move secured its place as a key European operator, and it created further acquisition opportunities in a European mobile market that was fragmented but rapidly beginning to consolidate.

In China, Vodafone made a strategic alliance with China Mobile with an investment of $\$ 2.5$ billion in October 2000 , which gave it a foothold in the world's largest mobile market, while China Mobile gained access to Vodafone's marketing and technical expertise, particularly in third-generation mobile technology. Meanwhile the group's initial investment in Japan followed from the merger with AirTouch, and comprised taking equity stakes in nine regional mobile telecoms companies. This created the option for further investment, which led to J-Phone Vodafone and the acquisition of Japan Telecom. Vodafone has also recently acquired Alltel Corp for $\$ 28$ billion.

However, when a serial acquisition vision overrides rational analysis, it may be vulnerable to cognitive drawbacks that can undermine objective decision making. Extensive psychological experimental studies suggest that there are general human biases in decision making that appear to affect decisions in predictable ways. ${ }^{2}$ Serial acquirers should try to mitigate the biases of their boards that may be responsible for suboptimal acquisition decisions and also try to anticipate-rationally-that their rivals, financial analysts, or investors can sometimes act in ways that can be predictably irrational. There are pitfalls that can manifest themselves in a biased strategy, ${ }^{3}$ in overheated contests for platform targets, or in the overvaluation of targets. 


\section{Potential Pitfalls in Serial Acquisition Strategy}

Pitfall 1:

Overinvestment or Over-Conservatism in Consolidating Industries

Acquisitions are surrounded by uncertainty, and how they are described or framed is likely to affect the way executives perceive the levels of risk involved. ${ }^{4}$ Aversion to losses is a central feature of Kahneman and Tversky's prospect theory (a descriptive theory, based on extensive experimental evidence) of how people evaluate risk. ${ }^{5}$ Decisions are determined by gains and losses measured relative to a reference point. Loss aversion-meaning that people are more sensitive to the possibility of losses than to gains of the same magnitude-may lead executives to behave in a way that is suboptimal from the shareholder perspective. Confronted with acquisition decisions in a consolidating industry, executives may exhibit aversion to a certain loss and narrow framing.

A CEO may tend to avoid taking a "certain loss" by refusing to abandon bidding contests or to divest assets. For instance, Vodafone was accused of excessive bidding in repeatedly raising its bid (up to a 70\% premium) to win its hostile takeover battle against Mannesmann's management. Similarly, when a market entry decision is considered at a loss relative to a reference point-for instance, where the price to be paid for a platform acquisition exceeds its standalone value-management may choose to continue making risky investments in an unattractive region hoping to gamble their way out, rather than to divest the platform at a lower but certain loss.

A CEO may also look at a strategic platform acquisition in too narrow a way. Experimental evidence shows that when people are offered a new gamble, they tend to evaluate it in isolation, separately from other risks. ${ }^{6}$ This tendency is called "narrow framing" and can occur in platform acquisitions in particular, because the payoff distribution of an investment is much easier to understand in isolation than it is in the overall context of a serial acquisition strategy that involves interdependent follow-on investments and/or acquisitions in other regions. Thus, a company considering a platform acquisition as a one-shot deal will tend to underestimate its importance and behave too conservatively, risking undermining its strategic position. Clearly, too-narrow framing was one bias that did not affect Chris Gent: while Vodafone was capturing its leading position, some of its rivals remained conservative, unable to appreciate the new growth opportunities. However, Vodafone was clearly not in conservative mode and framed its strategy much more broadly, targeting multiple or parallel platform acquisitions in the U.S., Europe, China, and Japan to position itself to be able to make follow-on asset acquisitions across multiple geographies.

In summary, aversion to certain losses and too-narrow framing may result in an overly static acquisition strategy that will result in sub-optimal growth in shareholder wealth. However, while narrow framing may result in a too-conservative acquisition strategy that fails to fully utilize upward potential, aversion to sure losses can lead to a consolidator overinvesting, increasing his losses by continuing to invest when the market signals indicate otherwise-in essence, throwing good money after bad. 
Pitfall 2:

Judgment Biases Result in Overinvestment in an Acquisition Strategy

While the first strategy pitfall can result from the way executives perceive risk, Pitfall 2 results from the way they estimate risk and other critical factors. A management team may envision a well-crafted long-term consolidating strategy that involves the selection of a series of targets to secure its strategic position and to capitalize on-or even catalyze-industry consolidation. However, judgment biases reinforced by groupthink and disregard for warning signals can mean that the strategy they envision is based on overly optimistic expectations of synergies and the illusion of control over the targets. ${ }^{7}$

One such judgment bias that CEOs may face, and which can result in unrealistic entries, is overconfidence. ${ }^{8}$ Experimental evidence has shown that people tend to be overconfident, and this factor can be particularly true-and particularly tempting -in the kind of environment that typically surrounds highly successful executives who may have already executed a string of value-accretive transactions. ${ }^{9}$ Such managerial hubris - the unrealistic belief held by bidding managers that they can manage the assets of a target firm more efficiently than its current managers-goes hand in hand with excessively optimistic expectations. ${ }^{10}$ In the same way that behavioral corporate finance studies show that start-up entrepreneurs usually have overly optimistic views of their ventures' potential for success, ${ }^{11}$ executives involved in serial acquisition strategies can overestimate their company's ability to appropriate a target and thus overvalue its growth potential. ${ }^{12}$

This kind of bias in a serial strategy may be path-dependent, since the acquiring company's past successes (or recent media praise for its CEO) can increase the risk of overconfidence. ${ }^{13}$ Thus, previous successful acquisition efforts can introduce an overly optimistic view about the achievability of followon targets and can increase the danger of managers trying to take the company a "bridge too far." Table 1 provides an overview of simple boardroom experiments that reveal senior executives' sensitivity to cognitive drawbacks that may introduce judgmental biases affecting their ability to rationally perceive their acquisition strategy. While experiments such as "Feeling Confident?"14 ought to cause executives to look again at the rationality of their own belief in their abilities, it is worth remembering that overconfidence is a general self-serving human bias, and one that, sadly, appears to be only minimally affected by feedback.

In particular groupthink and team decisions tend to accentuate the risk of unwarranted confidence in the acquisition decision. Team groupthink can support the underestimation of the risks involved and so lead to the illusion of control. CEOs and top management teams often (sometimes unconsciously) credit their own actions when they succeed, but blame "bad luck" when they fail.

A related judgment bias in strategy design lies in a subconscious resistance to critically testing hypotheses. Seeing only what we want to see is labeled confirmation bias: experiments show we tend to seek confirmatory data and opinions, which leads on to systematic overconfidence in favored hypotheses. This type of general bias-investing more energy into looking for evidence that supports a 
hypothesis than into seeking signals that might contradict it—is revealed in the "Confirmed!" card experiment described in Table $1 .{ }^{15}$ Confirmation and overconfidence in strategy can also partly result from (or be reinforced by) other biases, such as groupthink. Group processes are sensitive to joint confirmation bias: imagine a group of executives and their consultants evaluating whether a postacquisition integration would realize the synergies they expected when they bid for the acquisition. Just as in the experiment in Table 1 participants choose cards that support (rather than contradict) their hypothesis, executives-supported by their business development teams, consultants, and investment bankers (who are, after all, incentivized to complete, rather than abort, transactions)-rarely seek or are presented with data that contradict a transaction's value proposition.

Where significant decisions that can materially affect the value of the organization are to be taken, the benefits of looking for potentially contra-indicatory evidence are clear. Nevertheless, executives often persist instead in seeking yet more confirmation, which does not necessarily provide new information value. $^{16}$

\section{Potential Bidding Pitfalls}

Even if the above-mentioned obstacles to their acquisition strategies have been successfully negotiated, executives face another challenge to successful execution: the bidding contest, which appears in its starkest form in bidding auctions and bidding wars. As noted above, Vodafone fought several takeover battles in what was a rapidly consolidating industry. Auctions are seen as efficient ways to match bidders and targets—smooth-running, swift, and fair. However, when they are structured over several rounds but with limited time for advisors to plough through information in data rooms (as is common in private equity auctions and privatizations) the threat that bidders can become overcommitted is increased. This process is similar in competitive bid situations for public companies: in either case, the costs-financial, emotional, and reputational-will escalate as the process unfolds.

\section{Pitfall 3:}

Entrapment in an Escalating Bidding Contest

Consider the classic thought experiment "War of Attrition" (described in Table 2) that shows how two rivals engaged in a bidding war can end up paying much more than the object is worth to justify their initial bidding expenses, a tendency that is exacerbated by the competitive instinct typical for behavior in an auction.

Irrational escalation of commitment (commitment bias) reflects the choices of decision makers who are unwilling to admit that they were mistaken to have gone this far in the first place. Decision makers can too often persist in bidding even after the price exceeds the target value, simply to justify the actions that they have already taken. This often arises in situations in which the bidding process is costly, but there still appears to be a possibility of achieving better outcomes by continuing to bid. As noted, Vodafone had to outbid Bell Atlantic 
TABLE I. Biases that Affect Company Strategy

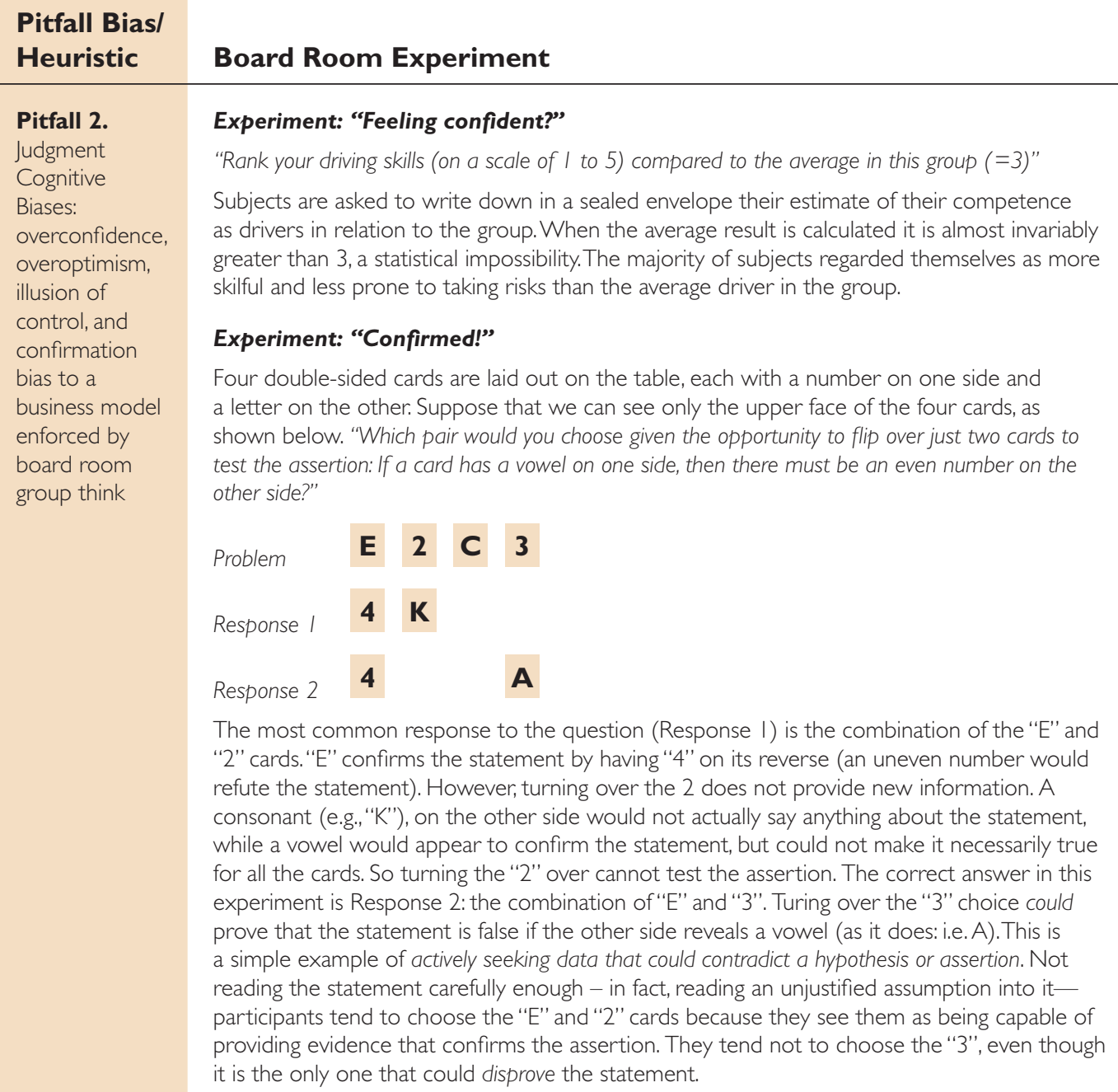

\section{Experiment: "Confirmed!”}

Four double-sided cards are laid out on the table, each with a number on one side and a letter on the other. Suppose that we can see only the upper face of the four cards, as shown below. "Which pair would you choose given the opportunity to flip over just two cards to test the assertion: If a card has a vowel on one side, then there must be an even number on the other side?"

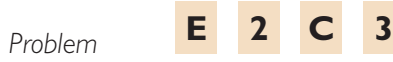

\section{Response / 4 K}

Response $24 \quad$ A

The most common response to the question (Response I) is the combination of the "E" and "2" cards. "E" confirms the statement by having "4" on its reverse (an uneven number would refute the statement). However, turning over the 2 does not provide new information. A consonant (e.g., "K'), on the other side would not actually say anything about the statement, while a vowel would appear to confirm the statement, but could not make it necessarily true for all the cards. So turning the "2" over cannot test the assertion. The correct answer in this experiment is Response 2: the combination of "E" and " 3 ". Turing over the " 3 " choice could prove that the statement is false if the other side reveals a vowel (as it does: i.e. A). This is a simple example of actively seeking data that could contradict a hypothesis or assertion. Not reading the statement carefully enough - in fact, reading an unjustified assumption into itparticipants tend to choose the "E" and "2" cards because they see them as being capable of providing evidence that confirms the assertion. They tend not to choose the " 3 ", even though it is the only one that could disprove the statement.

Note: There are three categories of psychological pitfall that may cause suboptimal serial acquisition strategy: biases, heuristics and framing effects.

- A bias is a predisposition to an error of some type.

- A heuristic or a rule of thumb, based on experience, industry standards or academic constructs. It is not uncommon for managers to rely on heuristics in their valuation of targets, but their unquestioned use as substitutes for rigorous fundamental analysis may affect optimal decision making

- Framing concerns the way the decision is described, and often influences executives' decisions.

to buy AirTouch for $\$ 62$ billion and was also forced to pay a substantial $(70 \%)$ premium over the prevailing market price to win its hostile takeover battle for Mannesmann.

Entering a bidding contest is costly-bidders have to pay fees to their bankers, legal advisors, and consultants, whose reputations will often be as much on the line as those of the focal company and its executives. Executives 


\section{Description of Human Biases that Affect} Strategy Decision Making

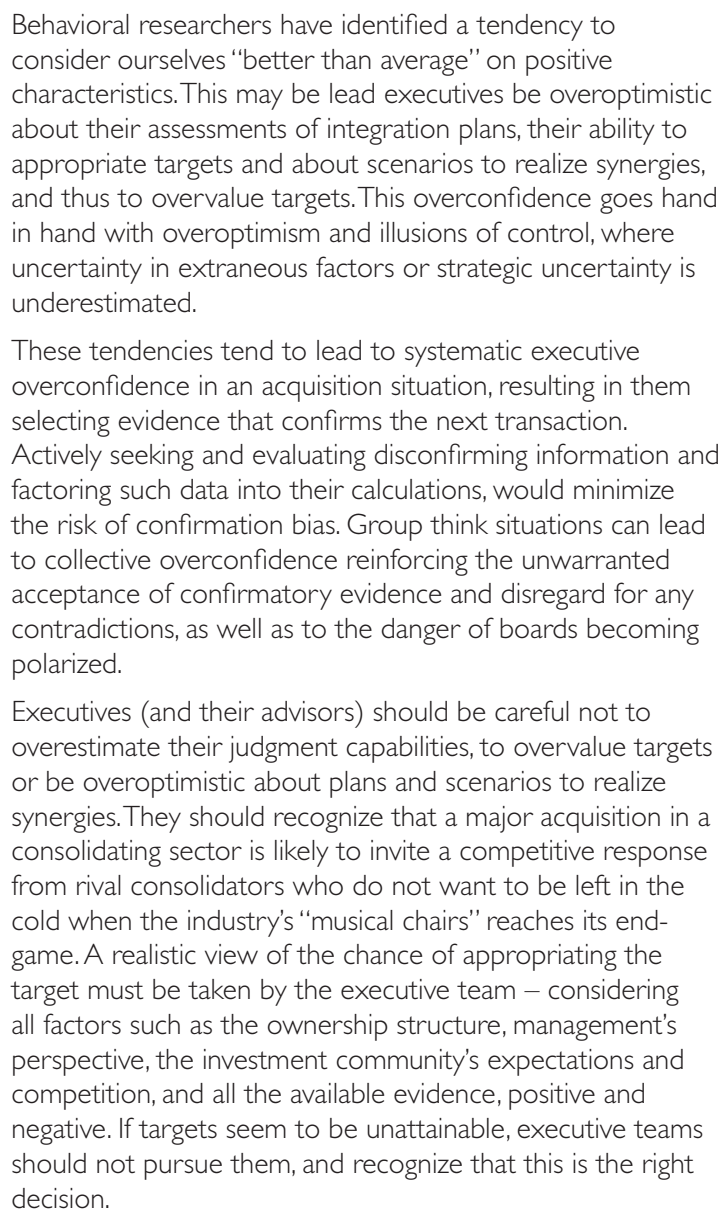

hate to admit that their past investments were ineffective, and what better way to reaffirm the value of their earlier acquisitions than by becoming even more committed to them through further investments? Group dynamics also play a role. Executive teams and even boards become invested in the bid process, creating rationales to show why walking away would cost more in terms of reputation, momentum, loss of key skills, or even share price pressure. Pressure from their bankers can often reinforce such group logics for pressing on-“one more 
TABLE 2. Biases that Affect Bidding

\begin{tabular}{|c|c|c|}
\hline $\begin{array}{l}\text { Pitfall Bias/ } \\
\text { Heuristic }\end{array}$ & Board Room Experiment & $\begin{array}{l}\text { Description of Human } \\
\text { Biases that Affect } \\
\text { Bidding }\end{array}$ \\
\hline \multirow{4}{*}{$\begin{array}{l}\text { Pitfall } 3 . \\
\text { Escalated } \\
\text { Commitment }\end{array}$} & Experiment: "War of Attrition" & \multirow{3}{*}{$\begin{array}{l}\text { Escalation reflects the decision } \\
\text { makers' unwillingness to admit } \\
\text { they were mistaken to go this far } \\
\text { in the first place. It often arises } \\
\text { in situations in which the bidding } \\
\text { process is costly, but there seems } \\
\text { to be a possibility of achieving } \\
\text { a better outcome by bidding } \\
\text { further. Bidders should ignore the } \\
\text { impact of prior investments if they } \\
\text { are sunk. }\end{array}$} \\
\hline & $\begin{array}{l}\text { A } £ 5 \text { note is auctioned between two rivals in an } \\
\text { English (i.e. ascending price) auction. Bids increase } \\
\text { by } € \text { l per round until one bidder gives up and the } \\
\text { other wins the } £ 5 \text { note. However, in this format the } \\
\text { loser and the winner still both pay their highest bid. }\end{array}$ & \\
\hline & \multirow[t]{2}{*}{$\begin{array}{l}\text { In practice, the winning bid often exceeds } £ 5 \text {, since } \\
\text { neither rival wants to give up and pay their bid } \\
\text { unnecessarily. The above example is in some sense } \\
\text { similar to a company auction, with advisory fees and } \\
\text { other sunk costs. }\end{array}$} & \\
\hline & & $\begin{array}{l}\text { The situation resembles waiting } \\
\text { for a friend - if you have already } \\
\text { invested } 15 \text { minutes, you are more } \\
\text { likely to invest another } 5 \text { - if you } \\
\text { have already invested an hour, you } \\
\text { are more likely to invest another } 15 \\
\text { minutes. }\end{array}$ \\
\hline \multirow{5}{*}{$\begin{array}{l}\text { Pitfall } 4 . \\
\text { Winner's Curse } \\
\text { (can result } \\
\text { from bias and } \\
\text { information } \\
\text { asymmetry) }\end{array}$} & Thought Experiment: "The Winner's Curse" & \multirow{4}{*}{$\begin{array}{l}\text { When the value of the asset } \\
\text { being auctioned is uncertain, the } \\
\text { winner is likely to overestimate } \\
\text { its worth and bid too high. Even } \\
\text { relying on a good valuation } \\
\text { method can leave some } \\
\text { uncertainty. A rational bidder } \\
\text { should submit a bid at a price that } \\
\text { is lower than their uncertain value } \\
\text { estimate - and the less accurate } \\
\text { the valuation, the lower the bid } \\
\text { should be. }\end{array}$} \\
\hline & $\begin{array}{l}\text { An undisclosed amount of small change in a wallet } \\
\text { (taken randomly from a group member) is auctioned } \\
\text { among the group. Bids are sealed and the highest } \\
\text { wins the unknown amount. }\end{array}$ & \\
\hline & $\begin{array}{l}\text { "What would you bid for an asset with an unknown } \\
\text { value?" }\end{array}$ & \\
\hline & \multirow{2}{*}{$\begin{array}{l}\text { Participants will want to bid a margin below their } \\
\text { estimate (which is inevitably uncertain, and made } \\
\text { on guesswork rather than evidence) to allow for } \\
\text { profit, but high enough to win the auction. However } \\
\text { the dynamic created by the combination of the } \\
\text { uncertain value and selection of the highest bid } \\
\text { often results in the winner being the bidder who } \\
\text { most overestimates the target's value - which they } \\
\text { subsequently regret. }\end{array}$} & \\
\hline & & $\begin{array}{l}\text { The main lesson is the } \\
\text { importance of gathering as much } \\
\text { information as possible about the } \\
\text { true fundamental value of the } \\
\text { assets being sold. }\end{array}$ \\
\hline
\end{tabular}

price increase will do it" - to the point of ignoring dissenting voices or contraindicating data.

This kind of escalation is, at least in part, related to the sunk cost fallacy-a phenomenon where increased investments are made mainly to justify cumulative prior decisions, even in the face of new evidence suggesting that the original decisions were probably wrong. When previous transactions along the serial acquisition path were justified on the basis of future transactions, it becomes even more difficult for a team to later back off from one of those future transactions, considering they have "come this far along the road" in their serial acquisition strategy. 
In a serial acquisition strategy, the premium paid for a platform acquisition that can be viewed as a precursor to the current target can also be seen as a "sunk cost" - thus acting as a further incentive to overpay once more. Worse still, powerful arguments can be made that the entire serial acquisition strategy will stall or even fail unless the current target is acquired at all costs. Previous expenditures—such as on due diligence, consultancy, financing, or even on a previous high premium platform acquisition-should never be used as arguments by themselves to continue bidding. They should be ignored, unless their nature and any associated learning provide real insights into whether it makes sense to continue.

Pitfall 4:

The "Winner's Curse" —Successful Bidding on Inaccurate Information

However, bidders in auctions are not only vulnerable due to irrationally escalated bidding: inaccurate information can also lead auction bids to exceed the value of the acquisition. At the time of Vodafone's expansion, the winner's curse was quite common in the telecoms industry, in auctions for licenses and bidding contests for acquisitions. ${ }^{17}$

When several bidders contemplate the acquisition of the same target company, they may not know the target's exact value when they bid. Where "good" information as to the target's value is difficult to come by, or just uncertain, bidders are obliged to fall back on trying to estimate its value independently. When the company is worth (roughly) the same to all bidders, the only thing that distinguishes them will be their respective valuation estimates. The winner will thus be the one that makes the highest estimate. If, in fact, the average bid is accurate, then the highest bidder will have overestimated the target's value, so (by definition) the winner is likely to have overpaid-the winner's curse.

Consider a simple numerical example of two different companies being auctioned. One with a well-defined value deriving from ascertainable cash flows (A) and the other (B) with an uncertain value based on growth options. Suppose the value of company A is $\$ 2$ billion: as this value is known, bidders will bid just under that level—high enough to outbid rival bidders, low enough to leave the transaction profitable. The range of bids will, therefore, be quite restricted, since they will be based on "good" information.

However, in the company B case, where the asset is of (comparatively) unknown value, the increased uncertainty implies a much wider distribution of bids, since they are all based (more or less entirely) on estimates. Suppose the bids vary from $\$ 1$ billion to $\$ 3$ billion, with an average, measured by the mean of their distribution, of $\$ 2$ billion (incidentally, the same as for Company A). As the auction rules ensure both companies are sold to the highest bidders, it is likely that company A's acquirer will have paid somewhat less than $\$ 2$ billion. However, the acquirer of the uncertain target $\mathrm{B}$ is the one that most overestimated its value - this "cursed" winner will pay $\$ 3$ billion.

Imagine now the auctioning of an item of uncertain value when some bidders know more about the item than others-i.e., a situation of informa- 
tion asymmetry. Anyone who has bought antiques at an auction will know the unpleasant feeling that creeps up on you when you have just outbid a professional trader or collector. They know more than you-you have almost certainly paid too much. Bidders who fail to take the possibility of information asymmetry into account are even more likely to fall afoul of the winner's curse.

A situation that illustrates the winner's curse of "hard to value assets" was the 2000-2001 auction of 62 UMTS (3G) licenses in the European telecoms market, which realized a total of $€ 109$ billion. Operators trying to consolidate their pan-European markets needed footholds in four key markets: France, Italy, Germany, and the UK. Buying several licenses sequentially would give them economies of scope and scale that would result in stronger strategic positions. The UK $3 \mathrm{G}$ network license, therefore, represented a platform investment, and the high prices paid in this auction partly reflected the extra value that was expected to result from follow-on investments in later auctions. The winners would benefit from a full-scale expansion, while those less successful would have a more restricted set of future opportunities. However, like the auctioning of many assets with elusive value, the sale led to a winner's curse. Market misperceptions of the value of these licenses were amplified by operators' overconfidence in their abilities to increase scale, and this cumulative overvaluation caused even the average bid to be higher than the true value, further increasing the winning bid and the burden of the winner's curse. A fundamental (e.g., real option) valuation could have resulted in a clearer view of the worth of the optionality, while at the same time incorporating uncertainty into the value estimation model.

Even when a good valuation method is available, uncertainty will remain. A rational bidder should take account of the danger of the winner's curse and submit a bid that is lower than the value estimate; and the more uncertain the valuation, the lower the bid should be. ${ }^{18}$ A seller should recognize that bidders' awareness of the winner's curse may lead them to bid more cautiously. Indeed, sellers at private equity auctions can be observed doing everything they can to limit uncertainty for buyers, e.g., by providing strategy reports from consultants and approved leverage from financiers.

It is crucial to make every effort to improve information about a target, certainly to a level higher than that of other bidders.

\section{Potential Valuation Pitfalls}

In addition to the pitfalls in the strategy and bidding processes, the assessment of value by the executive team (or by the financial market community at large) can provide yet another pitfall for companies seeking to acquire. Although Vodafone was accused of paying too much for its acquisitions in the early 2000s, in fact the entire sector proved difficult to value, and hindsight has shown it was over-valued.

When company value is elusive and hard to quantify, as when trying to assess the growth potential of platform acquisitions, the tendency is to revert to the heuristics of relative values (rules of thumb) that may over- or underestimate target values and rely too little on fundamental valuation methods. Market 
inefficiencies can lead to financial markets failing to price firms correctly, and the resultant inaccurate market valuations inevitably influence acquisition decisions. ${ }^{19}$ Irrationality in financial markets affected both the valuation and the financing of Vodafone's acquisitions.

Pitfall 5:

Relative Valuation with Insufficient Adjustment

Relative (rather than absolute) valuing, often utilizing heuristics, can introduce flaws into the process of valuing a target. The common human tendency to rely too heavily on one characteristic or piece of already known information when making decisions represents a cognitive bias that has been described as "anchoring." Estimates and decisions are based on familiar positions or known "anchors," with insufficient adjustment being made relative to this known starting point. In terms of valuing, these heuristics can entail anchoring the offer on an earlier price, either taken from transactions involving comparable companies (or perhaps the target itself) but without making appropriate adjustments.

During normal decision making, individuals anchor (or overly rely) on specific information or a specific value and then adjust that value to account for other elements. However, once the anchor is set, there is usually a bias toward that value. Take, for example, an executive supported by advisors deciding to set an offer price on a target. They may start from the basis of prices paid for similar companies, and then use "multiples" (e.g., Enterprise Value to EBITDA and Price/Earnings multiples) as their basis for refining their valuation of the company, rather than considering how well the target company and its strategy fit into the bidder's own strategy. The valuation may suffer from related biases, e.g., "representativeness," where the valuation is overly dependent on relative valuation compared to its peers or to a rival bid.

Again, insufficient adjustment to an early anchor figure can lead an acquirer to underbid or to overpay. The boardroom experiment "Anchor and Adjustment" (in Table 3) illustrates the dangers of such cognitive drawbacks in the valuation analysis of target companies. ${ }^{20}$

$$
\begin{aligned}
& \text { A relative multiple analysis should only function as a reality check on a fundamental valu- } \\
& \text { ation, utilizing tools such as NPVs augmented with real options to determine the value of } \\
& \text { current operations and growth options. }
\end{aligned}
$$

Pitfall 6:

Mispricing in Financial Markets: Beauty is in the Eye of a Beholder

The analysis becomes more complex when (already biased) bidders observe rival bidders and attempt to account for their actions and reactions. The "Biased Beauty Contest" game (see again Table 3) can be a metaphor for thinking about multiple valuations in financial markets. ${ }^{21}$ Sometimes the price seems to be determined by the "perception of beauty" of others, who in their turn might be basing their perceptions on their view of how others perceive the "beauty" of the target. Pricing in financial markets and bidding in the pri- 
TABLE 3. Biases that Affect Company Valuation

\begin{tabular}{|c|c|c|}
\hline $\begin{array}{l}\text { Pitfall Bias/ } \\
\text { Heuristic }\end{array}$ & Board Room Experiment & $\begin{array}{l}\text { Description of Human } \\
\text { Biases that Affect } \\
\text { Valuation }\end{array}$ \\
\hline \multirow{5}{*}{$\begin{array}{l}\text { Pitfall 5. } \\
\text { Biases in } \\
\text { Valuation } \\
\text { Analysis: } \\
\text { Anchoring } \\
\text { and insufficient } \\
\text { adjustment, } \\
\text { representative, } \\
\text { available and } \\
\text { affect heuristics }\end{array}$} & Experiment: "Anchor and Adjustment" & \multirow{4}{*}{$\begin{array}{l}\text { In relative valuation we base } \\
\text { estimates and decisions on familiar } \\
\text { positions or "anchors," and often } \\
\text { make insufficient subsequent } \\
\text { adjustments relative to that starting } \\
\text { point. Even in fundamental valuations, } \\
\text { we tend to "work to a given value" } \\
\text { when uncertainty is involved. }\end{array}$} \\
\hline & $\begin{array}{l}\text { This experiment shows how we anchor our } \\
\text { estimates. A valuation team is asked two questions: }\end{array}$ & \\
\hline & $\begin{array}{l}\text { "Is the number of countries in Africa more or less than } \\
\text { [a high or low random number]?" and "How many } \\
\text { countries do you believe there are in Africa?" }\end{array}$ & \\
\hline & \multirow{2}{*}{$\begin{array}{l}\text { Participants given a low random number in the } \\
\text { formulation of the first question tend to significantly } \\
\text { underestimate the number of countries when } \\
\text { answering the second question, while those given a } \\
\text { high random number in tend to overestimate their } \\
\text { second answer. }\end{array}$} & \\
\hline & & $\begin{array}{l}\text { A valuation may be biased if it is } \\
\text { based on readily available information } \\
\text { relative to less salient information } \\
\text { (the "availability" heuristic), or when } \\
\text { valuation and decisions are based on } \\
\text { intuition (the "affect" heuristic). }\end{array}$ \\
\hline \multirow{5}{*}{$\begin{array}{l}\text { Pitfall } 6 . \\
\text { Excess Pricing } \\
\text { in Financial } \\
\text { Markets: } \\
\text { Biased beauty } \\
\text { contest }\end{array}$} & Experiment: "Biased Beauty Contest" & \multirow{3}{*}{$\begin{array}{l}\text { Sometimes the price seems to be } \\
\text { determined by the "perception } \\
\text { of beauty" of others, who in their } \\
\text { turn might base their "perception } \\
\text { of beauty" on what they think our } \\
\text { perception is. Relative valuation of a } \\
\text { target can therefore be risky if the } \\
\text { benchmark is itself mispriced and } \\
\text { does not rely on fundamental analysis. }\end{array}$} \\
\hline & $\begin{array}{l}\text { Participants are asked to write down a number } \\
\text { between } 0 \text { and } 100 \text { such that their guess will be as } \\
\text { close as possible to } 2 / 3 \text { of the average guess in the } \\
\text { group. }\end{array}$ & \\
\hline & \multirow{2}{*}{$\begin{array}{l}\text { Behavioral economists use this experiment to } \\
\text { show the bounds of rationality in game theory. A } \\
\text { player might think that the average participant is } \\
\text { not involved and that their average guess will be } \\
50 \text {. So they guess } 33 \text {, which is } 2 / 3 \text { of } 50 \text {. The next } \\
\text { order of sophistication in "thinking how others } \\
\text { think" incorporates the view that the other guessers } \\
\text { will understand the same first level of thinking, and } \\
\text { so assume that they will guess } 33 \text { on average, and } \\
\text { therefore select } 22 \text { (as } 2 / 3 \text { of } 33 \text { ). }\end{array}$} & \\
\hline & & \multirow[t]{2}{*}{$\begin{array}{l}\text { The relative appreciation of an } \\
\text { acquirer can be used as means of } \\
\text { financing its follow-on acquisitions } \\
\text { (e.g., Vodafone's market appreciation } \\
\text { helped it to acquire targets in bidding } \\
\text { contests by paying in shares). }\end{array}$} \\
\hline & $\begin{array}{l}\text { Game theorists search for an equilibrium - that is, a } \\
\text { number which, if everyone guessed it, no one would } \\
\text { have any incentive to change their guess: in this } \\
\text { instance, that number would be } 0 \text {. }\end{array}$ & \\
\hline
\end{tabular}

vate equity world sometimes work in the same way, with bidders basing their "guesses" as to a target's value on their perceptions of other bidders' estimates. ${ }^{22}$

In a consolidating industry, the dynamics of relative value are markedly more acute than for acquisitions in simpler sectors, since targets take on increasingly strategic meaning as the industry consolidates. Beyond its scarcity value, the same target may play a particular role in the serial acquisition strategies of, or offer unique synergies to, one or more bidders, with the result that different parties may have (perhaps markedly) different views as to its value. When bidding managers and financial analysts both use comparable methods, the valuations of assets acquired for specific strategic reasons (which may be unique to one acquirer) can lead to misperceptions about their value for the entire sector. 
Market prices can also deviate from fundamental value (as happened in the dotcom bubble that affected the financial markets during the early 2000s). Given the vulnerability of financial market valuations to environmental turbulence, therefore, unless a particular target has unique strategic value (for example, as part of a premeditated serial acquisition strategy) or offers significant synergies, buyers would be well warned to assess critically the validity of comparable or relative valuations.

Financial markets were at the peak of their irrational exuberance at the turn of the millennium and, with "new economy" firms in hot demand into 2001, may have greatly overvalued the telecoms industry's growth opportunities. Serial acquirers sometimes chose to finance their acquisitions with shares, both to take advantage of relative appreciation within the sector, and at the same time to hedge against whole sector mispricing by financial markets. Vodafone countered the anxieties expressed about the costs of its serial acquisition strategy in this period by paying with its own shares, so as to benefit from the general re-rating of the telecoms industry at the time-in effect, they served as a useful "currency" helping to mitigate the potential for overpayment for its "fully priced" targets.

\section{Can Rational Analysis Discipline Strategy?}

Executives need to be constantly aware of their potential biases if they are to protect themselves from making suboptimal decisions in their strategies, in their company valuations, and in their bidding decisions. However, awareness alone may not be sufficient to ensure a successful consolidation strategy: psychologists have demonstrated that recognizing our errors and biases does not necessarily lead us to be able to correct them and go on to more rational decision making.

A quantification using a "rational" real options ${ }^{23}$ and games analysis approach may offer further help in mitigating the effects of several cognitive biases. The advantage of integrating game theory into the options approach is that it explicitly recognizes value erosion and the interaction of rival bidders playing the game of "musical chairs" for available acquisitions under conditions of uncertainty.

In this view, bidding on a platform acquisition should be based on an expanded NPV criterion:

$$
\begin{gathered}
\text { Expanded NPV }= \\
\text { (standalone value of platform-price) } \\
+ \text { added value of future (shared) synergistic opportunities }
\end{gathered}
$$

This starts with the platform's standalone value and expected synergies but also uses real options to take into account the potential for follow-on acquisitions, as well as using game theory to predict the strategic impact of rival bids. When a target is offered at an auction, or when multiple bidders make an offer for a publicly traded firm, value can be eroded if other buyers seem likely to 
bid up the price. To avoid overpayment, executives should use financial market valuations as a top-down objective view of growth option value that confirms or disconfirms the added value of consolidation, rather than depending solely on subjective management information.

\section{Illustration:}

\section{Vodafone's Acquisition Strategy as a Portfolio of Real Options}

The successful way to structure a list of target options into a consolidation strategy is to map alternative acquisition paths - that is, to adopt a "lattice" approach, mapping long-term contingent series of acquisitions and organic investments against the key uncertainties that, as they are resolved, could change the available options. With the help of some hindsight, Figure 1 presents a simplified illustration of the staged decision structure of Vodafone's strategy and of the synergistic opportunities arising from its acquisitions or alliances. ${ }^{24}$ The sequential acquisition strategy stages are represented as branches of a tree. Exercising its UK acquisition options gave Vodafone a dominating home market position that provided it with a platform that enabled it to pursue a worldwide network expansion strategy and leverage the competences it gained into followon acquisitions, as well as enhancing its cash flows via various cost and marketing efficiencies.

The various types of acquisition options are the building blocks of a serial acquisition strategy. A real options analysis requires the team to identify explicitly the various types of options (e.g., platform investment or asset divestment options) and to use option valuation methods (e.g., the binomial model) to value the set of real options embedded in the organization and its businesses. (Several of these acquisition options types are described in Figure 1.)

First, the option characteristics of different types of potential acquisition targets must be considered. Acquisitions that realize their benefits primarily through synergies or through expected earnings streams (or operating cashflows) are classified here as asset acquisition options. For instance, Vodafone pursued a strategy of acquiring follow-on options in existing operationssequentially increasing its shareholdings in Vodafone Libertel (Netherlands), Vodafone-Panafon Hellenic (Greece), Vodafone Telecel-Comunicacoes Pessoais SA (Portugal), and Europolitan Vodafone AB (Sweden) - the fundamental rationale for which was simply to deliver growth. A minority stake $\mathrm{e}^{25}$ that creates an advantaged opportunity for the holder to increase its stake in a target can be viewed as "call option" on the company value (its underlying asset), with the "bid" as the exercise price and time to maturity equal to the horizon of the acquisition opportunity.

A platform acquisition option, ${ }^{26}$ however, involves a higher growth option value than an asset acquisition option, since it involves an option on the underlying call options. A platform acquisition-be it to access an emerging market or a joint venture where firms combine resources—can be a critical component in a serial acquisition strategy. Such an acquisition derives a significant part of its value by creating a new path for follow-on investment opportunities, thus altering both 
the position of the enterprise and its strategic course. (Likewise Vodafone gained a strong platform in the U.S. when it outbid Bell Atlantic for AirTouch.)

The defining characteristic of a platform acquisition is that it provides a powerful step into a new environment and access to a new array of future investment opportunities, perhaps including access to a new geography. If synergies and future options prove sufficiently valuable, follow-on acquisitions can be made that will further enhance the consolidator's position in its new market.

Vodafone executed a series of opportunistic platform acquisitions to position itself for multiple follow-on acquisitions using the buy-and-build principle. Serial acquisitions represent conditional platform trajectories that establish specific targets and have "intersections" at several junctures in time, as well as define a limited number of possible outcomes for an industry endgame. Vodafone's platform acquisitions in the U.S., Europe, China, and Japan each provided a basis for growth in that region.

For this kind of real option application, a discrete-time binomial analysis might be the most appropriate approach. The initial decision to invest in a platform can be made by first creating a number of industry endgame scenarios and then solving them backwards to evaluate all future potential outcomes of a proposed consolidation strategy. The idea is to begin with the growth potential of each platform at the terminal nodes in the decision tree, and then reason backwards to determine the optimal decision to make at each key point. Often, exit or mature continuing values are modeled as the end node of the binomial tree of a portfolio of options, using binomial option pricing or simulation. ${ }^{27}$ Reasoning backwards from each scenario and examining each potential juncture at which a platform acquisition and follow-on investments can be made also permits the development of a multitude of path segments for each of the company's major competitors, so generating valuable insight to what their possible moves might be, and thus into the relative value of each target to each competitor. ${ }^{28}$

Overcoming Pitfall 1: Real Options Can Mitigate Effects from Narrow Framing or Aversion to Certain Losses

Aversion to a certain loss may result in overinvestment even when all signs warn otherwise, while narrow framing can mean potential buyers are not taking full advantage of acquisition opportunities' upward potential, thus missing the boat in a consolidating industry. The real options approach supports a more adaptive and opportunistic strategy, as the currently envisioned acquisition trajectory is not regarded as static. Rather, the approach allows for the opportunistic revision of targets and periodic adjustments in the number and pattern of investments, depending on market growth or unexpected external developments. When the success of a serial acquisition strategy is redefined in terms of options and uncertainty, it provides a rationale for implementing, altering, or deferring decisions, depending on the evolution of the external environment.

First, a real options approach can mitigate the biases that lead to a conservative strategy being based on too-narrow framing. A platform acquisition is no longer considered in isolation, but rather as a first link in a chain of investments, 
FIGURE I. Staged Decisions in Vodafone's Buy-and-Build Acquisition Strategy

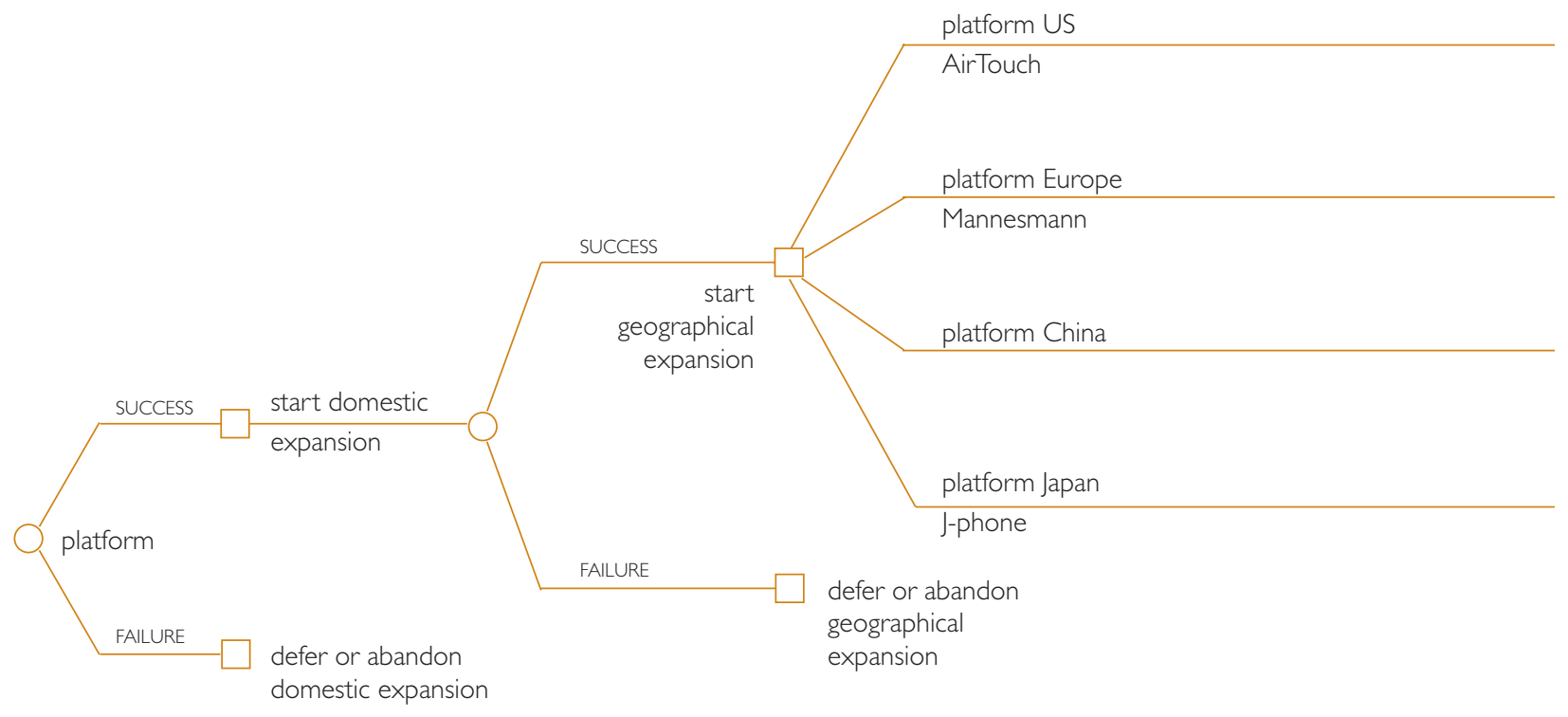

\begin{tabular}{ll}
\hline Category & Description \\
\hline $\begin{array}{l}\text { Stage I } \\
\text { Multiple or Parallel Platform Options } \\
\text { (Series of Compound Growth Option) }\end{array}$ & $\begin{array}{l}\text { Platform businesses with domestic (UK) reputations and competencies } \\
\text { provided the basis to leverage core competencies and marketing } \\
\text { capailities into a broader geographical base. }\end{array}$ \\
\hline $\begin{array}{l}\text { Stage II } \\
\text { Timing of Asset Acquisitions } \\
\text { (Simple Timing Option) }\end{array}$ & $\begin{array}{l}\text { Consolidation, building up scale in a fragmented market.Vodafone } \\
\text { continued to consolidate- or increase stakes in existing investments- } \\
\text { as long as the net synergies of the acquisition and growth options at } \\
\text { that time were sufficiently valuable. }\end{array}$ \\
\hline
\end{tabular}

where earlier investments are prerequisites for those that follow. Interestingly, according to real option theory, business risk or dispersion of future company 


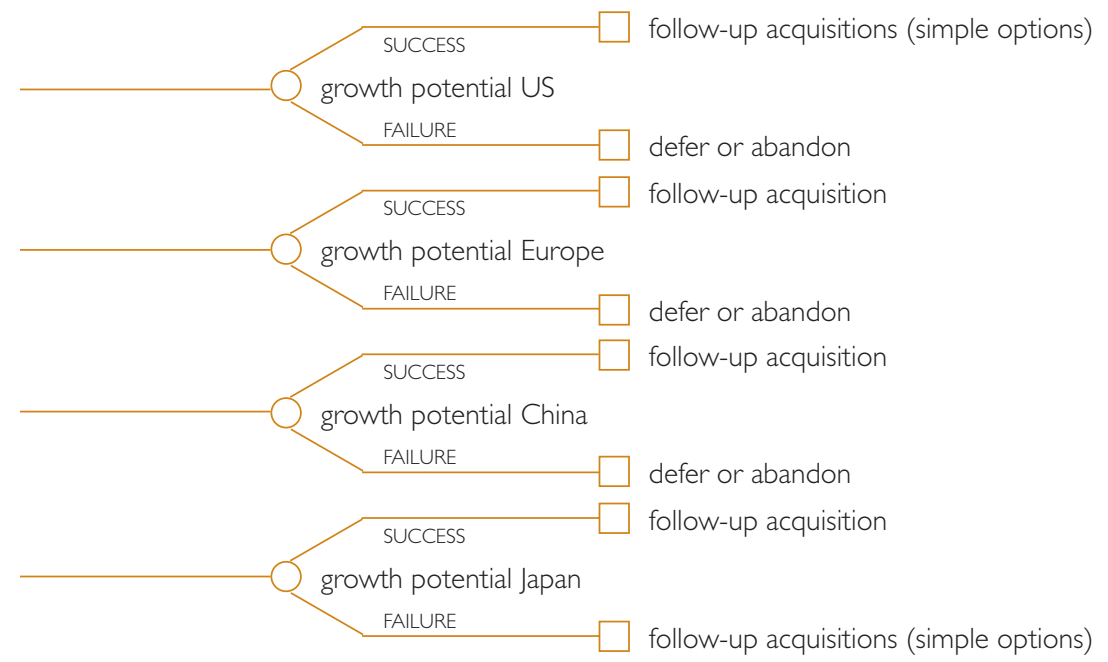

\section{Option Definition}

A platform acquisition is a compound option - an option on options. The platform can be viewed as a call option on follow-on investment opportunities (i.e. as an underlying call option), with the exercise price as the follow-on target price and the time to maturity being equal to the horizon. Valuing a series of parallel compound options is more complex, since it may involve a collection of interacting sequential options, which has an additional operating value derived from the opportunity to benefit from uncertainty through the coordination of subsidiaries that may be geographically dispersed (e.g., see Kogut and Kulatilaka, 1994).

Each opportunity for an acquirer to bid for or increase its stake in a target can be viewed as a call option on the company value for the bidder (i.e. an underlying asset), with the initial bid as the exercise price and time to maturity being equal to the horizon of the acquisition opportunity. This resembles a call option on the value of synergistic benefits where the exercise price is the cost of the merger.

\section{Example}

Having built a domestic platform in the UK, the acquisition of similar sized rivals — such as AirTouch in the US, (1999), Mannesmann in Europe (2000 and Japan Telecom (200 I) — quickly increased Vodafone's scale and diversity. These platform acquisitions shaped Vodafone's future acquisition opportunities and merger alternatives by creating a world-class brand, offering access to North America, Europe, China and Japan and significant scale as one of the world's largest telecoms companies.

Examples include smaller sized follow-on acquisitions in various geographies which saw Vodafone increasing its equity stakes in Vodafone Libertel (Netherlands), Vodafone-Panafon Hellenic (Greece), Vodafone TelecelComunicacoes Pessoais SA (Portuga), Europolitan Vodafone AB (Sweden), Airtel (Spain), Grupo lusacell (Mexico) and others.

values can exert a substantial positive influence on the value of real growth options and may justify (staged) acquisition decisions in uncertain areas. ${ }^{29}$ 
Second, appropriate use of a real options approach should help prevent overinvestment due to aversion to certain losses. Real options focuses on flexibility: as information about the success of a staged acquisition strategy is revealed, management can decide whether to proceed to the next stage or to alter or even terminate its future investment plans. A real options approach dictates that it is preferable to increase option value by staging acquisition processes in uncertain regions (such as emerging markets), first acquiring a minority stake or establishing a joint venture to gain entry into a new market, rather than rolling out investments quickly into commitment-intensive acquisitions.

Clear external thresholds or trigger levels-such as projected demand levels or critical product prices_-on which decisions should be based, or which indicate alternative actions (such as deferral or the pursuit of an alternative target), can force executives to adjust their decisions and so help avoid overcommitment due to an aversion to taking a loss. An ex ante option analysis will therefore differ from a biased analysis and should make it easier for executives to let go of intended targets without implying personal defeat. Thus, the options view should allow them to take full advantage of the upside potential created when events turn out better than expected, but still limit their losses on the downside.

Mitigating Pitfall 2: Which Judgment Biases Can a Real Options Frame Mitigate, and Which Can It Not?

Judgment biases among the top team will change the way a strategy is conceived and presented and will tend to implicitly support the assumption that things will turn out exactly as predicted in the strategic plan. An illusion of control may lead to a static strategy that continues to aim at acquiring intended targets, irrespective of whether they are no longer attractive or relevant in a changing business environment. The real options view does not consider the successful execution of a serial acquisition strategy as being a process that is entirely under the "control" of the executives, but rather as one that is partly conditional on the external uncertainty and subject to extraneous events.

A real options approach analyses the business environment by assigning probability distributions and values to uncertain macroeconomic, industry or business developments. Explicitly requiring management to model external uncertainty limits the self-serving bias where an executive team unconsciously credits its own actions when acquisitions succeed and invokes bad luck when they fail. To help overcome insufficient adjustment to (historic) starting points or anchors, forward-looking tools such as real options avoid treating their targets' intentions as a static scenario but instead adjust acquisition paths dynamically depending on uncertain developments.

Confirmation enforced by groupthink may also bias the acquisition plan in a static way, and real options can help mitigate this problem to some extent. A platform acquisition or entry into a new geographic market has embedded option value precisely because it has the potential to create or exploit future investment opportunities, not predetermined commitments. 
A warning should be made as this point. Valuation models-especially real options-can be used for self-justification or rationalization. By framing acquisition opportunities as real options, one can start to see options everywhere and should take care to avoid taking an over-optimistic view of acquisitions' growth options to justify a higher bid. To suppress overvaluation of growth option values, targets should be selected from a comprehensive list, and care should be taken not to overestimate the levels of added value-either in terms of synergies or future options-associated with each opportunity. ${ }^{30}$ Judgment biases can also serve to increase the value of growth options so as to justify or rationalize intended investment decisions. This is a weakness of any valuation method including a real options analysis. One way of limiting overvaluation is to integrate real options analysis with game theory; another way is to check valuations against (presumably more) objective values in financial markets.

\section{How to Use Option-Games to Overcome Bidding Pitfalls}

Vodafone's hostile \$205 billion acquisition of Mannesmann in Germany was an example of escalated bidding. The European market was undergoing rapid consolidation and the limited acquisition opportunities in the industry were hotly contested. Vodafone had to secure its place as a key European operator against its main rivals such as Germany's T-Mobile. The enhanced value of Mannesmann to Vodafone stemmed partly from it representing a potential platform in Germany towards securing the dominating position in the consolidating European telecoms sector that Vodafone aimed at.

Suppose that the standalone value of Mannesmann could be estimated at $\$ 71$ billion, the synergies at $\$ 2$ billion, and the divestment options at $\$ 50$ billion. ${ }^{31}$ The expanded NPV with the additional strategic value component could therefore be calculated as follows:

$$
\begin{gathered}
\text { Expanded NPV }= \\
\text { (net stand-alone value of platform }+ \text { abandonment options) }- \text { price }) \\
+\begin{array}{c}
+ \text { expected synergies }+ \text { strategic growth option value from Mannesmann in European expansion }] \\
=[71+50-205]+[2+\text { strategic growth option value }] \\
=[\text { strategic growth option value }]-82
\end{array}
\end{gathered}
$$

So, even though Vodafone's acquisition gained it embedded platforms in two of Europe's most important mobile telecoms markets (Germany and Italy), justifying its final bid for Mannesmann involved effectively estimating the value of the strategic growth options involved at $\$ 82$ billion-a figure so high one could consider it unlikely. One could surmise, then, that Vodafone's preemptive bid was motivated (at least in part) by its desire to win, rather than fairly reflecting the fundamental growth option value of its acquisition.

Naturally, the growth option value for a consolidator created through potential future acquisition is the excess value of the target to the successful acquirer over the acquisition price, i.e., the firm's ability to extract a synergistic value from the acquisition beyond what it pays for it. In the option game 
approach, the potential of making acquisitions is valued on both their value and price characteristics. In this context the value of the acquisition is what the target is potentially worth to each bidder, based on the impact on that bidder's accumulation path. Price, on the other hand, is what the successful bidder ultimately pays. How a (simplified) option game of acquisition growth potential works is illustrated in the Sidebar. ${ }^{32}$

Value is what the winner gets, price is what the winner pays.

Overcoming Bidding Pitfall 3: Avoid Irrational Escalation in Bidding, but Play Poker by Betting Against Rival's Predictable Biases

Like the valuation of a call option, the value of the acquisition option game is determined by a backward induction process. Looking forward and reasoning back may help avoid biases due to the "sunk cost" fallacy or to over commitment, but encourages executives to let go when events turn out worse than expected.

In the build-up to an auction, a biased rival bidder will have a different market response to that of a rational bidder. Rivals who are biased and/or overconfident may fail to see all the consequences of their actions, so that while rational players perceive the decisions in a game clearly and consistently, their rivals may still base their decisions on heuristics or have psychological biases and so outbid them in auctions.

Acquisition games are therefore better applied if rationality is combined with insights from behavioral economics, so bidders can predict and thus rationally respond to their rivals' irrational behaviors. ${ }^{33}$ The rational bidder should take an opportunistic view and try to avoid battles that lead to escalating commitment to bidding. As noted, overcommitment arises in situations in which the bidding process is costly, but there still seems to be the possibility of achieving better outcomes by bidding further. This is particularly so when acquisition value is hard to ascertain, where there is interest from multiple bidders, or where bidders have experienced a recent period of successes in acquisition battles. While an overconfident and over-optimistic rival is hard to beat in a bidding contest without paying an excess premium, executives must remember that exiting the bidding game can also be a valuable option.

Rational bidders can "play poker" against biased rivals to take advantage of their psychological strategy biases. For instance, in the early stages of industry consolidation, rivals may have a conservative strategy and frame acquisitions too narrowly, holding them back from making risky consolidating acquisitions. Recognizing this bias allows a canny consolidator to identify where and when to make an early bid to avoid ending up in a bidding contest later in the game. Vodafone's aggressive build-up strategy allowed it to seize the initiative in a fragmented and growing telecoms market by moving before its rivals into an aggressive acquisition growth program that would enable the enlarged firm to gain increasing market share and become an industry leader in a growing sector.

Generally, acquisition options are not proprietary but are "shared" with rival bidders, creating a disincentive or additional costs to counterbidders. These 


\section{SIDEBAR: How the Option Game Valuation of Acquisition Opportunities Works}

Consider the case of two comparable bidders ( $\mathrm{A}$ and $\mathrm{B}$ ) each having the opportunity to acquire a target. An option games valuation works backwards based on the following steps:

- calculate the payoff values of the target for bidder $A$ and bidder $B$ in a $2 \times 2$ matrix (subgame);

- determine dominant bidding strategies and the Nash equilibrium in each $2 \times 2$ sub-game; and

- use option valuation to work backward in the binomial tree using the equilibrium values from the two sub-games in the up and down business cycle states.

The current value of the company for bidder $A$ equals $\$ 4 \mathrm{bn}$ and for bidder B $\$ 3.2 \mathrm{bn}$. Uncertainty in the cycle and company value is modeled by a lattice approach where the value can either move up $(u=1.25)$ or down $(d=0.80)$ depending on industry product demand.

\section{Payoffs in the 2x2 Matrix (bidding sub-game)}

Making a bid corresponds to taking or increasing a stake in a target. Exercising the option early may pre-empt the rival's acquisition opportunity, but deferring a bid is consistent with a cautious strategy that is less expensive, more flexible and safer in case of unfavorable economic developments. The figure below shows the payoffs in this economic uncertainty dilemma. Consider first the up-cycle scenario. The left $2 \times 2$ table summarizes the payoffs (bidder A, bidder B) in four investment-timing scenarios in an upward moving market situation:

(i) when both firms enter into a contest and bid (simultaneously) the total expected synergies are reflected in the price. Suppose that in the up-cycle the target value for bidder $A$ is $\$ 5 b n$ $\left(\mathrm{V}^{+}=\mathrm{uV}\right)$ and for bidder $\mathrm{B} \$ 4 \mathrm{bn}$. The bidding costs are equal at $\$ 0.5 \mathrm{bn}$. The NPV for bidder $\mathrm{A}$ equals the target private value for the bidder minus price minus bidding cost $(5-4-0.5=$ 0.5). Since bidder A assigns a higher value to the target (due to its complementary assets), bidder $B$ will be outbid and he will incur the bidding cost (minus $\$ 0.5 b n)$, resulting in a $(0.5,-0.5)$

payoff for each bidder, with bidder A capturing the target against B's value;

(ii)/(iii) when one investor bids while the other makes no offer, the bidder secures the target for $\$ 3.5 b n$ and captures a larger part of the value creation for themselves $(5-3.5-0.5=1$ for bidder $A$ ), resulting in a payoff of $(1,0)$ or $(0,0)$ respectively if $B$ bids and bidder $A$ does not enter $(4-3.5-0.5=0$ for bidder $\mathrm{B})$;

and (iv) when both firms decide to wait, they share the total additional value created by the timing flexibility equally, cushioning their downward losses. Suppose that this payoff equals $(0.75,0.25)$

\section{Dominant Strategies and Nash Equilibrium}

The next step is to identify dominant strategies in the above sub-game and determine the resulting Nash equilibrium. Dominant strategies are those actions that always give a player a higher payoff value than any alternative action, whatever the other player decides to do. 
Consider the equilibrium implications of an asymmetric payoff structure as in the bidding game described earlier and shown below. Suppose that bidder A's payoff for pursuing the acquisition (lower row) exceeds the payoff of letting it go (upper row), no matter which strategy Bidder $\mathrm{B}$ chooses $(\$ \mathrm{l} b \mathrm{bn}>\$ 0.75 \mathrm{bn}$ and $\$ 0.5 \mathrm{bn}>\$ 0 \mathrm{bn}$ ). Then bidder $\mathrm{A}$ has a dominant strategy to pursue the acquisition. Given this, firm B will not pursue the acquisition (since $\$ 0 \mathrm{bn}>-0.5 \mathrm{bn}$ ). The Nash equilibrium outcome of this game (marked *) is given by the down left cell $(I, 0)$, where bidder $A$ acquires the company against firm B's value.

We can perform a similar analysis for a down cycle. Here we assume the payoff in the righthand $2 \times 2$ matrix below, where neither firm can generate net synergies from the consolidation, and neither will make an offer, resulting in a $(0,0)$ payoff.

\section{Backward Option Valuation of Growth Opportunities (PVGO) along the Binomial Tree}

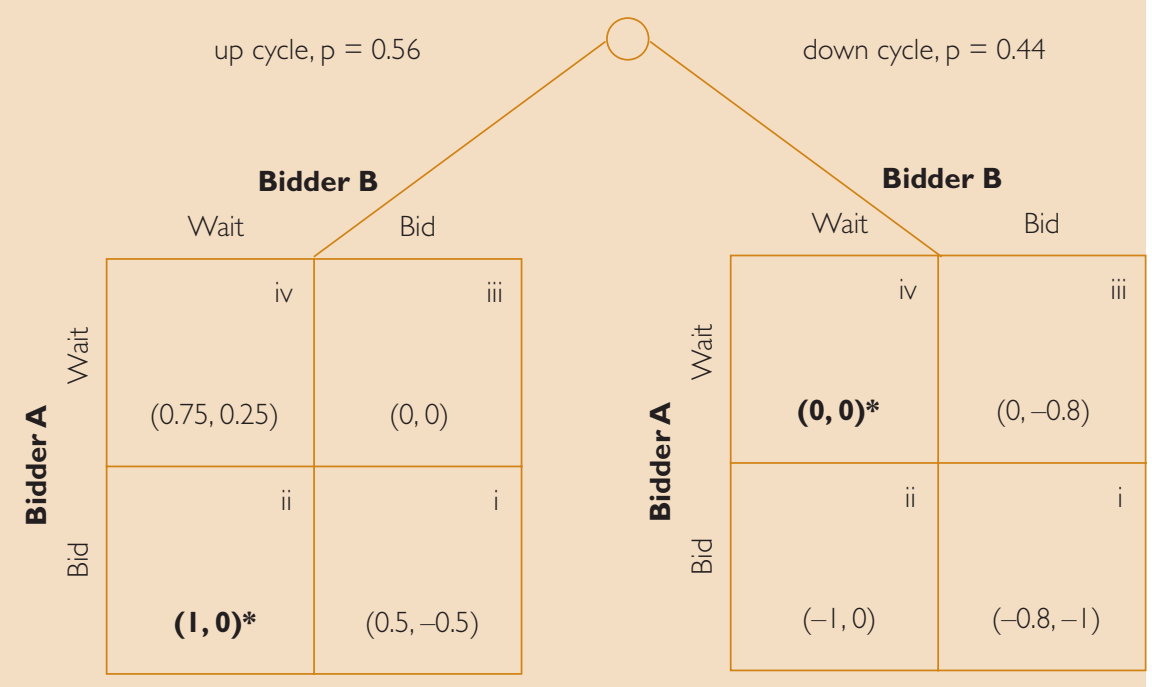

Note: Payoff in each cell is for (Bidder A, Bidder B); strategies of firm $A$ are wait (upper row) or bid (lower row); strategies of firm B are wait (left column) or bid (right column).

The risk neutral probability (following from the binomial option model) equals:

$$
p=\frac{(1+r)-d}{u-d}=\frac{(1+0.05)-0.80}{1.25-0.80}=0.56 \text {. }
$$

For the up and down cycle situations, the sub-games have (different) Nash equilibriums in pure strategies. As we have seen above (see also left $2 \times 2$ matrix), in the up cycle the advantaged bidder captures the opportunity (with Nash equilibrium values being ( $\$ \mid \mathrm{lbn}$ ) in box (ii). But in the down cycle, the Nash equilibrium is for both bidders to wait instead (thus receiving $\$ 0$ in box (iv) in the right hand $2 \times 2$ matrix above). The present value of the growth opportunity for bidder $A$ to acquire the target (PVGO) is the discounted weighted average of the Nash equilibrium outcomes across the up and down cycle states. 
Backward induction using the sub-games represented by the above two $2 \times 2$ matrices (under up vs. down cycle) results in a (sub-game perfect) equilibrium trajectory. The process moves backward over random demand moves using the associated risk-adjusted probabilities to calculate values at the beginning of the binomial tree. In determining the growth option value the average is computed as the risk-adjusted expectation of the two equilibrium outcomes ( I for high cycle, 0 for low cycle) using the risk-adjusted probabilities ( $p=0.56$ for an up-cycle trend and 0.44 for a down-cycle trend, with discounting performed at the "riskless" interest rate of $r=0.05)$.

$$
\mathrm{PVGO}_{\mathrm{A}}^{*}=\frac{0.56(1)+0.44(0)}{1.05}=0.53 \mathrm{bn}
$$

factors can help the acquirer secure its target and can also provide additional optionality to time the acquisition of a part-acquired target or of follow-on targets more effectively. (For example, a pre-investment in the form of a minority or blocking stake may increase the bidder's ability to gain control.) A bidder who can consolidate early in an industry on the threshold of a consolidation wave can enjoy significant advantages in acquiring companies and building competitive position compared to late movers. The revelation of the success of Vodafone's acquisition strategy triggered a series of mergers and acquisitions in the industry, changing the probability of success of specific strategies. In the endgame, rival consolidators may end up in a negative sum game, with intense competition for assets, overcommitment, and bidding wars reducing the economic pie by attracting capital into the industry at excessive levels relative to the potential returns.

Acquisition games are better modeled if rationality is combined with an understanding of the likely behavioral patterns and biases of rival bidders.

\section{Overcome Bidding Pitfall 4:}

\section{How to Avoid the Winner's Curse and Create a Unique Position}

To avoid the winner's curse, a rational bidder should try to gather information and develop an independent view about the fundamental value of what is being sold, both to the company itself and to its rivals. The winner's curse underscores the importance of relying on fundamental methods for valuing targets in competitive settings. In particular, when a target's value is elusive and there are multiple bidders, some may overvalue and others undervalue the assets being sold. Thus it is crucial that a firm makes every effort to improve its information about a target, certainly to gain superior information to that available to its rivals in a bidding contest.

Savvy bidders will avoid the winner's curse by "shading" their bid, setting it below their (ex ante) estimation of the uncertain value of the target. The less accurate their valuation (e.g., the higher growth option value it includes), the lower the bid should be. The severity of the winner's curse increases with the number of bidders, and also when the average bid is higher relative to exterior market conditions because of judgment biases. 
The winner's curse does not apply to all auctions. In the early stages of a consolidation there may be occasions when the average bid is too low relative to the target's fundamental value, e.g., when biased rivals are too conservative and have not yet recognized the target's potential strategic value to an acquirer. Similarly, bidders from different contexts-e.g., private equity bidder vs. a strategic player or consolidator vs. a non-consolidating bidder-are likely to assign different values to the same target. When the company has private value (e.g., when it generates unique synergies with one of the rival bidders), the winner's curse also does not arise.

The issue in developing paths is to what extent the acquirer can develop a unique and advantaged position (to appropriate further growth options) compared to other firms involved in similar buy-and-build strategies. The factors affecting each firm's growth options may also differ, generating significant differences in how they exercise and time their bids. It is precisely in these circumstances that the consolidating bidder's ability to assess the strategic value of a target as accurately as possible-within the context of its defined serial acquisition strategy-becomes essential to ensuring it continues to deliver sustained growth in shareholder value.

Company- and context-specific platform path dependencies will mean the value of a specific follow-on target to one potential acquirer is unlikely to equal its value to another, and this will cause a variance between its inherent value and the ultimate price different bidders are willing to pay. Organizational capabilities and their set of corporate real options-and the impact of uncertainty itself-will differ for each firm. Exercising the option to expand, for instance, is going to be more valuable for a consolidator than for a non-consolidating player, especially if the consolidator is a market leader by virtue of its size, earlier acquisitions, and complementary assets. Naturally, a realistic review of potential interlopers into the bidding process must be performed, as well as an evaluation of the unique incremental value of the target to each rival bidder, taking their different synergies and strategic objectives into account.

The optimal route for consolidators in these circumstances may well be to seize the advantage by taking preemptive action at relatively low prices, and target selection should be based on securing increasing advantage. If the consolidating company has already established a dominant position in its industry, the threat of preemption by a smaller rival is reduced, unless the rival is able to capture a blocking position-for example, by securing a small but decisive stake in a desirable target.

\section{Dual Valuation of Growth Option Value to Avoid Irrational Infection}

As with all analyses, the high degree of subjectivity inherent in designing acquisition paths and the variables used in real options analysis mean that the associated techniques can also be used inappropriately to justify a preferred course of action or higher bidding prices. ${ }^{34}$ The fundamental valuation of a con- 
solidation strategy should be subjected to a "reality test" by comparing it with the value of assets and growth options of industry players of different sizes and using various strategies. Shareholder value must be the key criterion in assessing an acquisition, so the value added by the consolidation strategy should ultimately equal the amount by which the future value of the consolidating firm exceeds the sum of the costs of its individual acquisitions and of any organic growth it pursues. This top-down analysis can function as a reality check on a fundamental valuation by using option game tools to determine the value of its current operations, their embedded options, and those that might arise from an intended acquisition.

When fragmented markets are ripe for consolidation, the appreciation of a company's value in financial markets may exhibit the following characteristics:

- Relative overpricing of bidders' equity compared to equity of targets in financial markets-Evidence suggests that takeover activity is strongly related to stock market valuation. ${ }^{35}$ The relative value of leading companies allows them to acquire serial targets relatively cheaply, taking advantage of their highly valued equity to finance their transactions. ${ }^{36}$ A serial acquisition strategy can be based on rational value drivers, but also on mispricing-the case of Vodafone seems to be consistent with these findings. Its acquisitions were concentrated in the period 1998-2000 when its share price was at its peak. Empirical studies also show that targets are in general undervalued relative to bidders, or at least less overpriced by financial markets. ${ }^{37}$ A bidder may try to select a target that offers better value for their higher value equity.

- The value of assets in place and implied growth options is relatively higher for leading corporations-When financial markets work efficiently, the company's full value, its growth opportunities, its strategic position in the industry and the economic logic of its consolidation activities should all be reflected in its stock price. The gap between the company's market value and the present value of the earnings capacity of its assets in place represents the value placed on the firm's strategy to appropriate profitable corporate growth opportunities—or its "implied PVGO," 38 i.e.:

$$
\text { Implied PVGO = Market Value (MV) - Assets in Place (PV) }
$$

Consider, for example, an estimation of the proportion of Mannesmann's 1996 stock price made up of the present value of its future growth options (PVGO/P). The (then) present value of its assets in place can be relatively easily estimated. Suppose that its 1996 earnings were DM22 per share and the cost of equity was $11 \%$, and assume that the earnings capacity of its current assets would have been constant under a hypothetical no-growth strategy. The perpetuity equation results in share values of DM200 for the capitalized value of its earnings from assets in place (under a no-growth policy). However, since Mannesmann's average 1996 equity price was DM550, the market's assessment of the PVGO embedded in its stock price amounted to DM350-some $64 \%$ of its stock market value. 
The value imputed from a growth option analysis is most helpful when considering the relative value of possible targets—or when considering the value of a specific target to different potential bidders. For consolidation to make sense, an efficient financial market should assign a higher value to leading companies' assets in place (PV) and growth opportunities than to those of smaller firms. The larger firms' lower cost of capital results in an appreciation of their assets in place. In addition, their better growth prospects should be reflected in higher PVGO-to-Price (and EV/EBITDA) ratios than those of smaller players. Vodafone's average PVGO-to-Price was only slightly higher than those of its largest acquisitions-such as AirTouch (PVGO-to-Price of $85 \%$ ) $^{39}$ or Mannesmann (PVGO-to-Price of 90\%), but considerably higher than its smaller targets (e.g., Libertel had a PVGO-to-Price of 69\%).

\section{Avoiding Pitfall 5: Bottom-Up Option Valuation} to Prevent Overreliance on Relative Values and Heuristics

Since the value of a strategic acquisition derives from its ability to enhance a consolidator's strategic position, the valuation of platform acquisitions requires careful scrutiny and more sophisticated competitive analysis than either suggested by heuristics or offered by a simple relative valuation. A combined real options and game theory framework can incorporate the elusive strategic value that is so hard to capture when using starting points or anchors. This analysis is beneficial in quantifying the merits of strategic alternatives and helping assess tradeoffs, so that "price tags" can be attached to investment decisions.

However, companies should be careful about inferring that rational analysis is "truth" - the misperception that once numbers are attached, data are "accurate." Although we argue that analysis can be sensitive to biases, we do not argue that strategic intuition is necessarily flawed. However, real options and game techniques can complement the intuitive strategic thinking process in a dynamic way that will be consistent with that strategy's underlying logic and design. It is essential to translate the qualitative discussion of projects into a proper options structure and identify its strategic elements. Game theory supplemented with options analysis helps to tackle the complex strategic problem involved in this process and reduce it to a simpler analytical structure. The framework it provides can also promote clear management recommendations for executable actions by guiding managers' decisions as to whether, when, and under what conditions investments would be appropriate.

Overcome Pitfall 6:

Can Financial Markets Provide an External View?

The PVGO measure is arguably contingent on market sentiment, and market inefficiencies mean market value (MV) may not reflect fundamental firm value. Empirical studies typically separate market value into intrinsic and mispriced elements. We can separate out these behavioral finance arguments in a new decomposition of firm value. 
This method "backs out" the value of the growth option set from the firm's equity value, but with the modification that the market value is adjusted for mispricing. The present value of growth options (PVGO) can be estimated from the value of assets in place and the adjusted market value of the firm. This is done by first using a pricing model to estimate the mispricing in the market value and deducting from the market capitalization (MV) both any excess (mispriced) value (XSP) ${ }^{40}$ as well as the present value (PV) component on the same basis as before (i.e., continuing current operations based on past investments or assets in place in a no-growth scenario and estimated using standard NPV techniques). The remaining (residual) equity value is taken to reflect the value of the firm's set of growth options (PVGO).$^{41}$ That is:

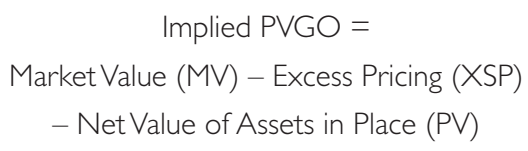

Firms in growth industries (e.g., computers, software, and drugs) tend on average to have a higher growth option value component (PVGO/MV) than firms in income industries for two reasons: first, they operate in more volatile and rapidly evolving industries (characterized by more frequent technological innovations and more intense competition), and this higher underlying volatility is translated into higher (simple) option values. Second, they tend to have a higher proportion of compound (multi-stage or growth) than simple (cash-generating) options, which (since these are options on options) further amplifies their strategic value. This higher growth option value, in turn, is translated into higher market valuations for these high-tech or growth stocks.

To help overcome the overconfidence bias in acquisition decision making, tools are required enabling the economic logic of strategy and financial valuation to interactively complement each other.

\section{Conclusions}

Many industries are witnessing accelerating consolidation trends-driven both by fundamental economic forces and behavioral biases-that will continue to dictate the value of consolidating companies and their targets. In order to be more successful than their competitors, organizations must seek ways to maximize their ability to identify and capture new opportunities, while also being able to respond appropriately to economic changes, by deferring or abandoning intended acquisitions or by contracting production capacity to limit losses from adverse market developments. The execution of a serial acquisition strategy is vulnerable to the way managers perceive risk and losses, judgment biases in their strategy, the bidding behavior of rivals, and mispricing in financial markets.

The various behavioral biases at play can make competitive interactions in the acquisition game increasingly complicated and sophisticated. The existing toolkit for company valuation and acquisition strategy-present value and traditional strategy approaches-falls short in resolving biases. We argue that 
using more sophisticated analysis, applying real options with extensions based on games theory and modified market valuations, can result in a strategy that is at once more rational and more dynamic.

When properly applied, the bottom-up real options-game approach is an attempt to support executive intuition concerning acquisitions with the discipline of a more rigorous analytical and rational process. The decision analysis should be complemented with a "top-down" PVGO quantification that uses direct information from financial markets to counter irrationality on the inappropriate use of the new tools to justify overpayment.

Vodafone's acquisition history provides an example of the behavioral dilemma involved in consolidation acquisitions. Although Vodafone's huge expansion was perceived to be built on the personal ambition of the CEO, without his efforts, Vodafone could not have expanded (via the platform acquisition of Mannesmann) to become the world leader it is today. Analyzing this dilemma with the approach advocated in this article requires:

- considering the acquisitions strategy through a real options lens;

- analyzing the price in the competitive bidding with a game theory extension; and

- a reality check using the top-down (PVGO) valuation.

First, we look at the growth strategy through a real options lens.

Although Vodafone's CEO was sometimes accused of managerial hubris (Pitfall 2 ), he framed Vodafone's strategy in a manner consistent with a real option view (and much more broadly than some of his conservative (Pitfall 1) competitors). From this perspective, Vodafone's Mannesmann acquisition delivered embedded platforms in two of Europe's most important mobile telecoms markets (Germany and Italy) as part of a global strategy targeting platform acquisitions across multiple geographies.

Second, the option game approach is not only about option values, but also about price and the bidding game. Even though Vodafone's Mannesmann acquisition provided a powerful step into new markets, to justify its final bid for Mannesmann effectively estimated the value of the strategic growth options involved at some $\$ 82$ billion-a figure so high one would consider it unrealistic from an option game perspective. One could surmise that Vodafone's bid might have been motivated in part by its desire to win (Pitfall 3) rather than fairly reflecting the target's fundamental real option value. The general market context made telecoms assets difficult to value, making auction bidders vulnerable to the winner's curse (Pitfall 4) and often overly dependent on relative valuation of the target's peers or of rival bids (Pitfall 5).

Third, top-down (PVGO) valuation requires that company valuation and financing take into account consideration of the (biased) appreciation of growth options in financial markets. Financial markets were at the peak of their irrational exuberance at the turn of the millennium and may have greatly overvalued the entire telecoms industry's growth opportunities (Pitfall 6). Following the insights from the top-down or market method, the excess pricing of Vodafone's 
own shares-as result of the general over-rating of the telecoms industry at the time-in effect gave it the potential to overpay for its fully priced targets. "New economy" firms were in hot demand into 2001 and it would be going too far to hold Vodafone responsible for the general overvaluation of the telecoms industry. However, the cost of its serial acquisition strategy and of building the company to be the world leader it is today was borne by those investors who bought Vodafone shares at the top of the cycle in $2001 .^{42}$

This example takes the specific case of Vodafone's Mannesmann acquisition to show the analysis our toolkit can provide compared to that of normal company valuation approaches. Note that (in general) the price paid under normal (PV) methods is typically less than our methods justify, since our tools allow for the greater appreciation of future potential (e.g., the platform acquisition of MIM by miner Xstrata, the platform acquisition of Pearle by a private equity investor HAL who built a global optical chain, or acquisitions by Vodafone before the change of the millennium).

This academic framework can assist executives of acquiring companies by helping them to discipline their strategy and thus improve their ability to participate successfully in consolidation trends in their industries by increasing their capability to value and bid for target companies successfully. Financial market analysts can also benefit from an improved understanding permitted by these new tools for identifying potential targets and valuing companies in consolidating industries. When properly applied, we believe the strategic option perspective can promote rational decisions, help identify when takeover premiums for certain platform acquisitions are justified and clarify the relationships between the restructuring of fragmented markets and the strategies and market values of specific companies.

\section{Notes}

1. Bell Atlantic later walked away from a partnership agreement with AirTouch. The intended strategic move would have led to an alliance between the two companies' cellular networks that would give them national reach.

2. The fundamentals of these behavioral economics have gained academic credibility in recent times. In 2002, two brilliant psychologists Daniel Kahneman and Vernon Smith shared the Bank of Sweden Prize in Economic Sciences-also called the Nobel Prize in Economics-for having integrated insights from psychological research into economic science, especially concerning human judgment and decision making under uncertainty. Financial economic and the psychological studies confirm that acquisition strategies can be vulnerable to managerial hubris. For instance, R. Roll, "The Hubris Hypothesis of Corporate Takeovers," Journal of Business, 59/2 (1986): 197-217; R. Roll, "The Hubris Hypothesis of Corporate Takeovers," in R.H. Thaler, ed., Advances in Behavioral Finance (New York, NY: Russell Sage Foundation, 1993), pp. 437-458; M. Baker, R. Ruback, and J. Wurgler, "Behavioral Corporate Finance: A Survey," in E. Eckbo et al., The Handbook of Corporate Finance: Empirical Corporate Finance (New York, NY: Elsevier/North Holland, 2004); N. Barberis and R. Thaler, A Survey of Behavioral Finance, Handbook of the Economics of Finance (Amsterdam: Elsevier, 2003); A. Shleifer, Inefficient Markets: An Introduction to Behavioral Finance (Oxford: Oxford University Press, U.K., 2000).

3. See for instance J.H. Barnes, "Cognitive Biases and their Impact on Strategic Planning," Strategic Management Journal, 5/2 (April-June 1984): 129-138.

4. When managers take risks and exhibit risk preferences they differ from the classical processes of choosing from among alternative actions in terms of the mean (expected value) and 
variance (risk) of the probability distributions over possible outcomes. See J.G. March and Z. Shapira, "Managerial Perspectives on Risk and Risk Taking," Management Science, 33/11 (November 1987): 1404-1418.

5. D. Kahneman and A. Tversky, "Prospect Theory: An Analysis of Decision under Risk," Econometrica, 47/2 (March 1979): 263-291.

6. For instance, see N. Barberis and M. Huang, "The Loss Aversion/Narrow Framing Approach to Stock Market Pricing and Participation Puzzles," in R. Mehra, Handbook of the Equity Risk Premium (Amsterdam: Elsevier, 2008).

7. D. Lovallo and D. Kahneman, "Delusions of Success: How Optimism Undermines Executives' Decisions," Harvard Business Review, 81/7 (July 2003): 56-63; D. Kahneman and D. Lovallo, "Timid Choices and Bold Forecasts: A Cognitive Perspective on Risk Taking," Management Science, 39/1 (January 1993): 17-31.

8. Experimental studies show that people hold a variety of self serving-biases, believing that they are more capable than that in fact they are. Such biases will lead to overoptimistic planning in the future. For instance, see L. Larwood and W. Whittaker, "Managerial Myopia: Self-Serving Biases in Organizational Planning," Journal of Applied Psychology, 62/2 (April 1977): 194-198.

9. "Reference group neglect" reflects a tendency to under-react to changes in the reference group one competes with. For example, see C. Camerer and D. Lovallo, "Overconfidence and Excess Entry: An Experimental Approach," The American Economic Review, 89/1 (March 1999): 306-318. Takeovers may result from CEOs overconfidence and hubris. For example, see Roll (1986), op. cit.

10. While overoptimism is reflected in an overestimation of a target's growth options and synergies, overconfidence concerns managers' views as to their abilities to capture these synergies or realize the acquisition.

11. A.C. Cooper, C.Y. Woo, and W.C. Dunkelberg, "Entrepreneurs' Perceived Chances for Success," Journal of Business Venturing, 3/2 (Spring 1988): 97-108.

12. The strategy is particularly vulnerable for over-investment when projects can be internally financed. See U. Malmendier and G. Tate, "Who Makes Acquisitions? CEO Overconfidence and the Market's Reaction," Journal of Financial Economics, 89/1 (July 2008): 20-43; U. Malmendier and G. Tate, "CEO Overconfidence and Corporate Investment," Journal of Finance, 60/6 (December 2005): 2661-2700.

13. U. Malmendier and G. Tate, "Superstar CEOs," Quarterly Journal of Economics, 124/4 (November 2009): 1593-1638; U. Malmendier, G. Tate, and J. Yan, "Does Overconfidence Affect Corporate Investment? CEO Overconfidence Measures Revisited," European Financial Management, 11/5 (November 2005): 649-659.

14. O. Svenson, "Are We All Less Risky and More Skillful Than Our Fellow Drivers?" Acta Psychologica, 47/2 (February 1981): 143-148.

15. These experiments and an overview of biases in exit decisions are discussed in J.T. Horn, D.P. Lovallo, and S.P. Viguerie, "Learning to Let Go: Making Better Exit Decisions," The McKinsey Quarterly, 2 (2006): 64-75. See also P.C. Wason, "Reasoning About a Rule," Quarterly Journal of Experimental Psychology, 20/3 (August 1968): 273-281.

16. See M. Jones and R. Sugden, "Positive Confirmation Bias in the Acquisition of Information," Theory and Decision, 50 (2001): 59-99.

17. However, in auctions with private value (i.e., when the target has a different value for each of the bidders) the winner's curse does not arise.

18. However, an actual overpayment will generally occur only if the winner fails to account for the winner's curse when bidding (an outcome that, according to the Revenue Equivalence Theorem, need never occur).

19. For instance, see R.J. Shiller, Irrational Exuberance (Princeton, NJ: Princeton University Press, 2000). Evidence shows that high market valuations are strongly related to merger activity [Rhodes-Kropf and Viswanathan (2004)] and managers of overvalued firms buy targets that are less overvalued [Rhodes-Kropf, Robinson, and Viswanathan (2005)]. M. RhodesKropf and S. Viswanathan, "Market Valuation and Merger Waves," Journal of Finance, 59/6 (December 2004): 2685-2718; M. Rhodes-Kropf, D.T. Robinson, and S. Viswanathan, "Valuation Waves and Merger Activity: The Empirical Evidence," Journal of Financial Economics, 77/3 (September 2005): 561-603.

20. The experiment in the table is based on A. Tversky and D. Kahneman, "Judgment under Uncertainty: Heuristics and Biases," Science, 185/4157 (September 1974): 1124-1131; F. 
Strack and T. Mussweiler, "Explaining the Enigmatic Anchoring Effect: Mechanisms of Selective Accessibility," Journal of Personality and Social Psychology, 73/3 (1997): 437-446.

21. This contest was performed in an article on behavioral finance written by renowned behavioral economist Richard Thaler, "Giving Markets a Human Dimension," Financial Times, Mastering Finance 6 section, June 16, 1997.

22. For instance, private equity investors should be careful with pricing secondaries-i.e., acquisitions from other private equity funds. In private equity, up to $80 \%$ in a DCF valuation of a buy-out results from a horizon or exit value that is often based on an exit EBIDA multiple, which in its turn is related to the entry multiple. If the entry multiple is incorrect, so is the exit multiple.

23. For articles on real options, see, for instance, W.C. Kester, "Today's Options for Tomorrow's Growth," Harvard Business Review, 62/2 (March/April 1984): 153-160; A.K. Dixit and R.S. Pindyk, "The Options Approach to Capital Investment," Harvard Business Review, 73/3 (May/June 1995): 105-115; M. Amram and N. Kulatilaka, "Disciplined Decisions: Aligning Strategy with the Financial Markets," Harvard Business Review, 77/1 (January/February 1999): 95-104. In the strategy literature, real options have been used for analyzing technology investments, international operations, and the ability of the firm to adapt to a changing competitive landscape. For instance, see E.H. Bowman and D. Hurry, "Strategy Through the Option Lens: An Integrated View of Resource Investments and Incremental-Choice Process," Academy of Management Review, 18/4 (October 1993): 760-782; B. Kogut and N. Kulatilaka, "Operating Flexibility, Global Manufacturing, and the Option Value of a Multinational Network," Management Science, 40/l (January 1994): 123-139; R.A. Bettis and M.A. Hitt, "The New Competitive Landscape," Strategic Management Journal, 16 (Summer 1995): 7-19; R.G. McGrath, "A Real Options Logic for Initiating Technology Positioning Investments," Academy of Management Review, 22/4 (October 1997): 974-996; B. Kogut and N. Kulatilaka, "Real Option Pricing and Organizations: The Contingent Risks of Extended Theoretical Domains," Academy of Management Review, 29/1 (January 2004): 102-110; R.G. Fichman, M. Keil, and A. Tiwana, "Beyond Valuation: 'Options Thinking' in IT Project Management," California Management Review, 47/2 (Winter 2005): 74-96.

24. For articles on real options and acquisitions or joint ventures, see K.D. Miller and T.B. Folta, "Option Value and Entry Timing," Strategic Management Journal, $23 / 7$ (July 2002): 655-665; T. Chi, "Option to Acquire or Divest a Joint Venture," Strategic Management Journal, 21/6 (June 2000): 665-688; T. Chi, "Performance Verifiability and Output Sharing in Collaborative Ventures," Management Science, 42/1 (January 1996): 93-109; T. Chi and D.J. McGuire, "Collaborative Ventures and the Value of Learning: Integrating Transactions Cost and Strategic Option Perspectives on the Choice of Market Entry Modes," Journal of International Business Studies, 27/2 (1996): 285-307; H.T.J. Smit, "Acquisition Strategies as Option Games," Journal of Applied Corporate Finance, 14 (Summer 2001): 79-89.

25. See Miller and Folta (2002), op. cit.

26. See B. Kogut and N. Kulatilaka, “Options Thinking and Platform Investments: Investing in Opportunity," California Management Review 36/2 (Winter 1994): 52-71. See also McGrath for an alternative conceptual framework of viewing real options as strategic platform investments. R.G. McGrath, “A Real Options Logic for Initiating Technology Positioning Investments," Academy of Management Review, 22/4 (October 1997): 974-996.

27. For most executives making acquisition decisions, partial differential equations represent an impractical and opaque framework. For fundamental option valuation we use a discretetime binominal valuation process (of a more complicated tree than that presented in Figure 1). Working backward from the industry endgame, decision makers can trace the values and intuit from the model the relative magnitude of values at each phase of the acquisition strategy. With higher complexity, much of the intuition of viewing acquisitions as real options may be sacrificed as the model takes precedent over the learning and insights it is designed to provide.

28. This is equivalent to the backward induction principle of option valuation and game theory. Starting at the end of the tree and working backwards, a valuation tree assigns values to outcomes such as undertaking mutually exclusive acquisition immediately, waiting to see how the market evolves, or forgoing any investments.

29. This insight, which may be surprising at first glance, hinges on the fact that if the platform entry fails, the follow-on acquisitions need not be made. In other words, if the entry fails, then only the relatively smaller foothold investment is lost. On the other hand, more can be gained from the riskier markets because of the better chance of exceptionally high returns in 
a growth stage. As a result, the growth option value today of the high-risk markets will be larger than otherwise similar low uncertainty markets (all other things equal).

30. It is worth sounding another word of caution with regard to the application of real options theory-the underestimation of the effects of option interaction. Real life transactions are often complex and may involve a collection of interacting real options. The valuation of flexible combinations resulting from the acquisition or merger should be based on an assessment of the interactive portfolio of options that captures the value resulting from the combination of the firms. Often the combined value of a collection of such real options differs significantly from the sum of the separate stand-alone option values. This combination of options may not always offer value that is greater than the sum of the parts. For instance, the option to abandon a company for salvage value may not add much relative to the option to default held by the shareholders of a highly leveraged firm. If the firm declares bankruptcy, most of this value will go to the bondholders. Similarly, a platform acquisition in a new geography may preclude platform acquisitions in other locations. It is important, therefore, that the value of the package of embedded options incorporates the impact of the interactions between these options, which is often less than the sum of the individual options valued using ready-made tools such as the Black-Scholes formula.

31. Vodafone agreed to divest Orange.

32. For an introduction to real options and options games, see H.T.J. Smit and L. Trigeorgis, Strategic Investment: Real Options and Games (Princeton, NJ: Princeton University Press, 2004). For a detailed analysis of an option game in airport expansion, see H.T.J. Smit and L. Trigeorgis, "Valuing Infrastructure Investment: An Options Game Approach," California Management Review, 51/2 (Winter 2009): 21-39.

33. C.F. Camerer, "Behavioral Studies of Strategic Thinking in Games," Trends in Cognitive Sciences, 7/5 (May 2003): 225-231.

34. Some would say this is just guesswork with numbers attached. For instance, see C. Smith, "M\&A as an Illusion," in Duncan Angwin, ed., Mergers and Acquisitions (Malden, MA: Blackwell Publishing, 2007).

35. For instance, see Rhodes-Kropf and Viswanathan (2004), op. cit.; M. Dong, D. Hirshleifer, S.H. Teoh, and S. Richardson, "Does Investor Misvaluation Drive the Takeover Market?" Journal of Finance, 61/2 (April 2006): 725-762.

36. A popular proxy for mispricing is the ratio of market value to book value. For instance, Rhodes-Kropf et al. [(2005), op. cit.] find that bidders have a larger MV/B than targets, but both have higher MV/Bs than non-mergers.

37. A. Shleifer and R.W. Vishny, "Stock Market Driven Acquisitions," Journal of Financial Economics, 70/3 (December 2003): 295-311.

38. $\mathrm{PVGO}=$ Market Value - Assets in Place $=$ MV - PV (earnings). See Myers (1977), op. cit. It is customary to normalize this equation by dividing the PVGO by MV. A related version of the equation above is suggested by Tony Tong and Jeffrey Reuer (2008), who estimate PVGO using economic value added: PVGO = Market Value $-($ Capital Invested + Present Value of Eco-economic Value Added). Both metrics measure the difference between market price and a more-or-less refined accounting value. Growth options value was first empirically studied by Kester (1984), op. cit. More recently, growth options value is has been related to systematic risk (Chung and Charoenwong, 1991), R\&D, uncertainty and the skewness of returns, to the pricing of initial public offerings (Chung, Minsheng, and Yu, 2005), to firm, industry and country effects (Tong et al., 2008), to downside risk of multinational corporations (Tong and Reuer, 2008), and to international joint ventures (Tong et al., 2008). K.H. Chung and C. Charoenwong, "Investment Options, Assets in Place and the Risk of Stocks," Financial Management, 20/3 (Autumn 1991): 21-33; K.H. Chung, L. Minsheng, and L. Yu, "Assets in Place, Growth Opportunities and IPO Returns," Financial Management, 34/3 (Autumn 2005): 65-88; S.C. Myers, "Determinants of Corporate Borrowing," Journal of Financial Economics, 5/2 (November 1977): 147-176; T.W. Tong, T.M. Alessandri, J.J. Reuer, and A. Chintakanda, "How Much Does Country Matter? An Analysis of Firms' Growth Options," Journal of International Business Studies, 39/3 (April/May 2008) 387-405; T.W. Tong and J.J. Reuer, "Real Options in Multinational Corporations: Organizational Challenges and Risk Implications," Journal of International Business Studies, 38/2 (March 2008): 215-230; T.W. Tong, J.J. Reuer, and M.W. Peng, "International Joint Ventures and the Value of Growth Options," Academy of Management Journal, $51 / 5$ (October 2008): 1014-1029.

39. For AirTouch, the 4 -year average $(92 \%$ in $1995 ; 89 \%$ in $1996 ; 77 \%$ in 1997 ; and $82 \%$ in 1998 ) is based on yearly average stock price before acquisition and a cost of capital of $11 \%$. 
For Mannesmann the 4-year average is based on $64 \%$ in $1996 ; 99 \%$ in $1979 ; 99 \%$ in 1998 ; and $97 \%$ in 1999 .

40. Mispricing can be assessed following the methodology as described by Rhodes Kropf et al. (2005), op. cit.

41. For an extensive empirical study on growth options value and mispricing, see S. van Bekkum, H.T.J. Smit, and E. Pennings, "Buy Smart, Time Smart," Financial Management (forthcoming, 2011). To estimate the fundamental price P, we adopt the methodology as recently applied in a takeover context by Rhodes-Kropf et al. [(2005), op. cit.] who estimate fundamental value (as opposed to observed market value) from an asset pricing model.

42. Obviously the initial investors of Vodafone were better off than the investors who bought at the top of the cycle. 
Copyright of California Management Review is the property of California Management Review and its content may not be copied or emailed to multiple sites or posted to a listserv without the copyright holder's express written permission. However, users may print, download, or email articles for individual use. 